\begin{tabular}{|c|l|}
\hline Title & Ice flow and isostasy of the north polar cap of Mars \\
\hline Author(s) & Greve, Ralf; Klemann, Volker; Wolf, Detlef \\
\hline Citation & $\begin{array}{l}\text { Planetary and Space Science, 51(3), 193_204 } \\
\text { https://doi.org/10.1016/S0032-0633(02)00206-4 }\end{array}$ \\
\hline Issue Date & 2003_03 \\
\hline Doc URL & http://hdl.handle.net/2115/35491 \\
\hline Type & article(author version) \\
\hline File Information & Greve_etal_2003_PSS.pdf \\
\hline
\end{tabular}

Instructions for use 
Planetary and Space Science 51 (3), 193-204, 2003

http://www.elsevier.com/locate/pss

— Authors' final version -

\title{
Ice flow and isostasy of the north polar cap of Mars
}

\author{
Ralf Greve (1), Volker Klemann (2), \\ and DetLeF Wolf (2)
}

(1) Fachbereich Mechanik, Technische Universität Darmstadt, Hochschulstraße 1, D-64289 Darmstadt, Germany

(2) GeoForschungsZentrum Potsdam, Abteilung 1: Kinematik und Dynamik der Erde, Telegrafenberg, D-14473 Potsdam, Germany

March 15, 2003

Correspondence to: R. Greve (greve@mechanik.tu-darmstadt.de) 


\begin{abstract}
The flow of the north polar cap of Mars, which is assumed to consist mainly of $\mathrm{H}_{2} \mathrm{O}$ ice, is investigated with the three-dimensional ice-sheet model SICOPOLIS. We consider a simplified topography and a climatic forcing varying between the present state and warmer, more humid conditions in the past with an obliquity cycle of 1.3 million earth years (yr). Furthermore, SICOPOLIS is coupled with the three-layer viscoelastic ground model displace to simulate the isostatic response of the underlying lithosphere/mantle system. Likely iceflow velocities at present are a few $\mathrm{mm} / \mathrm{yr}$, along with surface accumulation/ablation rates of the order of $0.1 \mathrm{~mm}$ water equiv./yr and basal temperatures more than $50^{\circ} \mathrm{C}$ below pressure melting. Thicknesses of the rheological lithosphere of 50-400 km are consistent with geothermal heat fluxes of $15-36 \mathrm{~mW} \mathrm{~m}^{-2}$, with some evidence for values of ca. $80-120 \mathrm{~km}$ and 20-30 $\mathrm{mW} \mathrm{m}^{-2}$, respectively. For an Earth-like upper-mantle viscosity of $\mathcal{O}\left(10^{21} \mathrm{Pas}\right)$, relaxation times of the lithosphere/mantle system are much shorter than significant load changes, so that the mantle behaves as an inviscid fluid. The poor correlation between the computed and measured free-air gravity signal indicates that it is determined by mass anomalies of a different origin.
\end{abstract}

\title{
1 Introduction
}

Both Martian poles are covered by surface ice caps, which vary considerably over the seasons. During the respective winter, these surface caps extend toward the equator beyond $55^{\circ} \mathrm{N} / \mathrm{S}$, whereas, in the summer, only much smaller residual ice caps survive within $80^{\circ} \mathrm{N} / \mathrm{S}$. Whereas the seasonal caps consist of a thin layer of $\mathrm{CO}_{2}$ snow, perhaps some $10 \mathrm{~cm}$ thick, the Mars Orbiter Laser Altimeter (MOLA) measurements of the Mars Global Surveyor (MGS) spacecraft revealed that the complexes composed of the residual caps and the underlying polar layered deposits are massive topographic structures, which rise about $3 \mathrm{~km}$ above the surroundings (Zuber et al. 1998, Smith et al. 1999a; Fig. 1a). Throughout this paper, we will refer to these complexes as the north and south polar cap, respectively, following the terminology of many recent publications (e.g., Johnson et al. 2000, Byrne and Murray 2002). The polar caps serve as cold traps for atmospheric water and highly likely consist of $\mathrm{H}_{2} \mathrm{O}$ ice with an unknown amount of mixed-in dust (Clifford et al. 2000). Therefore, they form small inland ice sheets in the meaning of terrestrial glaciology.

In a previous study by Greve (2000a), dynamic/thermodynamic model simulations were carried out for the north polar cap (NPC), approximated, for simplicity, as a paraboloidlike cap with volume, area and maximum thickness equal to those of the actual NPC. The NPC was investigated for three climate scenarios: present steady-state conditions or 

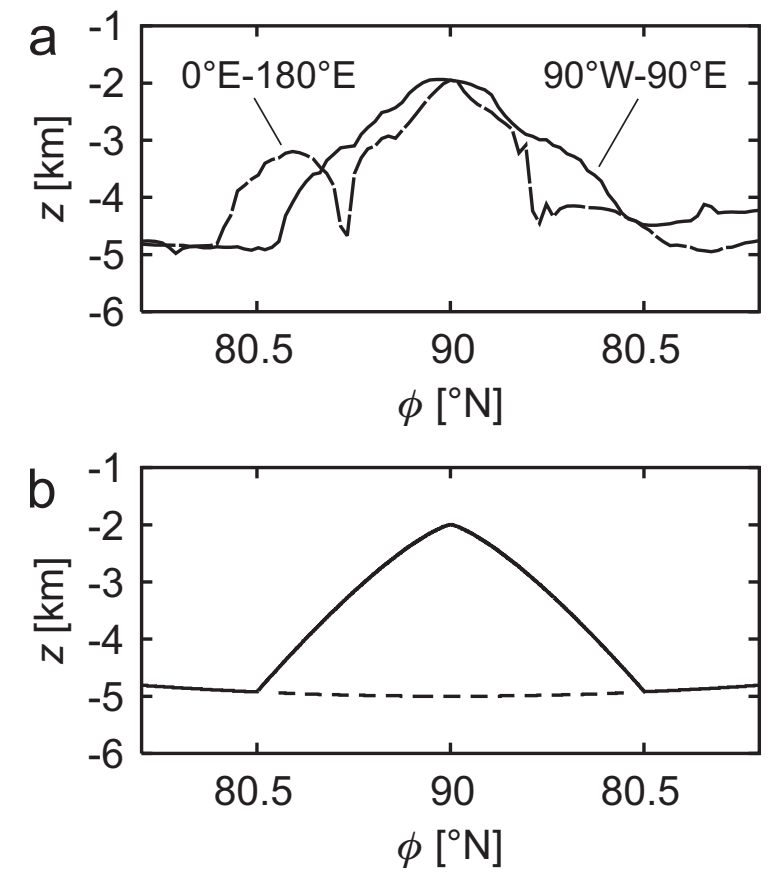

Figure 1: (a) Transects of the MOLA topography of the present NPC along meridians $90^{\circ} \mathrm{W}-90^{\circ} \mathrm{E}$ and $0^{\circ} \mathrm{E}-180^{\circ} \mathrm{E}$ (resolution $20 \mathrm{~km}$ ). (b) Simplified paraboloid topography (solid: surface, dashed: equilibrated ground) according to Eqs. (6) and (7). The actual ground will be lowered according to the isostatic compensation of the ice load.

periodically varying conditions between cold and arid at present and warmer and more humid in the past with periods of either $125 \mathrm{kyr}$ or $1.3 \mathrm{Myr}$ (where yr stands for Earth years), which are the main periods of obliquity variations (Kieffer and Zent 1992). It was found that the 1.3-Myr cycle is most likely responsible for oscillations of the ice extent between the present margin and a larger extent south to $75^{\circ} \mathrm{N}$ indicated by ice remnants (Zuber et al. 1998).

Here, we take up this result and extend the previous work by coupling the model of the NPC with a model of the dynamics of the underlying lithosphere/mantle system. Apart from investigating the major ice-dynamical questions of whether the NPC shows significant ice flow and whether the ice temperature allows for the presence of subglacial liquid water as a potential habitat for lifeforms, our aims are to constrain the present thickness of the rheological lithosphere and the geothermal heat flux, to compute the gravity anomaly due to the NPC and its compensation and to demonstrate that the gravity anomaly measured by orbit tracking of the MGS spacecraft results mainly from different sources such as mass anomalies in the ground. The latter finding confirms the results reported by Johnson et al. (2000).

Our central presumption is that the NPC is a dynamic $\mathrm{H}_{2} \mathrm{O}$ ice mass with physical properties comparable to those of the terrestrial ice sheets and, therefore, controlled by 
accumulation, ablation and glacial flow. This approach is controversial. Alternatively, one may argue that the NPC is a remnant of ancient, much larger ice masses, eroding away in the course of time without significant mass supply and flow. However, the absence of craters with diameters $>300 \mathrm{~m}$ indicates a low surface age of $\leq 100 \mathrm{kyr}$ (Herkenhoff and Plaut, 2000). Also, vanishing $\mathrm{H}_{2} \mathrm{O}$-ice accumulation at the surface is not likely (Clifford et al. 2000) and does not agree with albedo and imaging data (Bass and Paige 1999). Finally, our understanding of the physical properties of $\mathrm{H}_{2} \mathrm{O}$ ice requires the occurrence of glacial flow under the conditions that prevail for the NPC (Greve 2000a, Nye 2000).

\section{Modelling approach}

\section{$2.1 \quad$ Ice-sheet model}

The dynamic/thermodynamic behaviour of the NPC of Mars is investigated with the ice-sheet model SICOPOLIS (SImulation COde for POLythermal Ice Sheets), which was originally developed for terrestrial ice sheets like Greenland, Antarctica and the glacial northern hemisphere [cf. Greve (2000b) and references therein]. The model describes the material ice as an incompressible, heat-conducting, power-law fluid with thermo-mechanical coupling due to the strong temperature dependence of the ice viscosity:

$$
\boldsymbol{D}=E A\left(T^{\prime}\right) \sigma^{n-1} \boldsymbol{t}^{\mathrm{D}}
$$

where $\boldsymbol{D}=\operatorname{sym} \operatorname{grad} \boldsymbol{v}$ (velocity $\boldsymbol{v}$ ) is the strain-rate tensor, $\boldsymbol{t}^{\mathrm{D}}$ the Cauchy stress deviator, $\sigma=\left[\operatorname{tr}\left(\boldsymbol{t}^{\mathrm{D}}\right)^{2} / 2\right]^{1 / 2}$ the effective shear stress, $n$ the power-law exponent, $A\left(T^{\prime}\right)$ the flowrate factor [which depends exponentially on the temperature $T^{\prime}$ relative to the pressure melting point, see Greve et al. (1998)], and $E$ the flow-enhancement factor, which is equal to unity for pure ice and can deviate from unity due to the softening or stiffening effect of impurities in the ice. It is further distinguished between cold ice with a temperature below the pressure melting point and temperate ice with a temperature at the pressure melting point, the latter being considered as a binary mixture of ice and small amounts of water. The interface that separates cold and temperate ice is monitored using Stefan-type energy flux and mass flux matching conditions.

The model computes the three-dimensional temporal evolution of ice extent, thickness, velocity, temperature, water content and age in response to external forcing. The latter must be specified by (i) the mean annual air temperature at the ice surface, (ii) the surface mass balance, which is ice accumulation (snowfall, condensation) minus ablation (melting, sublimation, erosion), (iii) the global sea level (not relevant for Martian applications) 
and (iv) the geothermal heat flux entering the ice mass from below. However, for the simulations carried out in this study, instead of specifying the surface mass balance and computing the resulting topography evolution, the latter is prescribed, and the surface mass balance is computed such that it is consistent with the changing topography and the ice velocity field. This inverse approach has already been employed by Greve (2000a) and is pursued, because the MOLA data mentioned above have provided a very precise present topography of the NPC and an indication of its former extension (Zuber et al. 1998), whereas for present and past accumulation/ablation rates no direct measurements are available. The values of the relevant physical parameters used for the ice-sheet model are listed in Table 1.

\begin{tabular}{ll}
\hline Parameter & Value \\
\hline Gravity, $g=g^{(0)}$ & $3.72 \mathrm{~m} \mathrm{~s}^{-2}$ \\
Density of ice, $\rho_{\mathrm{i}}$ & $910 \mathrm{~kg} \mathrm{~m}^{-3}$ \\
Power-law exponent, $n$ & 3 \\
Flow-enhancement factor, $E$ & 3 \\
Heat conductivity of ice, $\lambda_{\mathrm{i}}$ & $9.828 e^{-0.0057 T[\mathrm{~K}]} \mathrm{W} \mathrm{m}^{-1} \mathrm{~K}^{-1}$ \\
Specific heat of ice, $c_{\mathrm{i}}$ & $(146.3+7.253 T[\mathrm{~K}]) \mathrm{J} \mathrm{kg}^{-1} \mathrm{~K}^{-1}$ \\
Latent heat of ice, $L_{\mathrm{i}}$ & $335 \mathrm{~kJ} \mathrm{~kg}^{-1}$ \\
Clausius-Clapeyron gradient, $\beta$ & $3.3 \cdot 10^{-4} \mathrm{~K} \mathrm{~m}^{-1}$ \\
\hline
\end{tabular}

Table 1: Values of the physical parameters used for the ice-sheet model.

\subsection{Ground model}

The isostatic response of the lithosphere due to the temporally varying ice load is simulated with the plain $n$-layer ground model displace (Wolf 1985a, Klemann and Wolf 1999). In the version used in this study, the incremental momentum equation applies to a continuum with hydrostatic pre-stress advection but without internal buoyancy (Wolf 1985b),

$$
\operatorname{div} \boldsymbol{t}^{(\delta)}+\operatorname{grad}\left(\rho^{(0)} \boldsymbol{g}^{(0)} \cdot \boldsymbol{u}\right)=\mathbf{0}
$$

with $\boldsymbol{t}^{(\delta)}$ the material increment of the Cauchy stress tensor, $\rho^{(0)}$ the mass density in the reference state, $\boldsymbol{g}^{(0)}$ the constant reference gravity directed vertically downward and $\boldsymbol{u}$ the displacement. In each layer, the material parameters are assumed to be homogeneous. The rheology of the continuum is that of a Maxwell-viscoelastic fluid,

$$
\boldsymbol{t}^{(\delta)}=(\kappa \operatorname{tr} \boldsymbol{e}) \mathbf{1}+2 \int_{0}^{t} m(t-\check{t}) \frac{\mathrm{d} \boldsymbol{e}^{\mathrm{D}}}{\mathrm{d} \check{t}} d \check{t}
$$


where $\boldsymbol{e}=$ sym grad $\mathbf{u}$ is the infinitesimal strain tensor, $\boldsymbol{e}^{\mathrm{D}}$ the corresponding deviator, $\kappa$ the elastic bulk modulus and

$$
m(t-\check{t})=\mu e^{-\frac{\mu}{\eta}(t-\check{t})}
$$

the shear-relaxation function for a Maxwell fluid expressed in terms of its elastic shear modulus $\mu$ and steady-state viscosity $\eta$.

The incremental gravity is calculated from the incremental Poisson equation,

$$
\operatorname{div} \operatorname{grad} \phi^{(\Delta)}=4 \pi \gamma \rho^{(0)} \operatorname{tr} \boldsymbol{e}
$$

with $\phi^{(\Delta)}$ the local increment of the potential at the reference height and $\gamma$ the gravitational constant. The free-air gravity increment is $\boldsymbol{g}^{(\Delta)}=\operatorname{grad} \phi^{(\Delta)}$ and the geoid displacement is given by $h_{\mathrm{g}}=\phi^{(\Delta)} / g^{(0)}$ (Bruns formula; $h_{\mathrm{g}}$ positive upward, $g^{(0)}$ is the magnitude of $\boldsymbol{g}^{(0)}$ ). For the axisymmetric problem considered here, the incremental field equations (2)-(5) are solved in the Hankel-wave-number, $k$, and Laplace-frequency, $s$, domains, where they reduce to a system of ordinary differential equations in terms of the vertical coordinate, $z$. After consideration of the ice load, the results are transformed back to the space-time domain by evaluating the inverse Laplace and Hankel transforms. Because the ice-surface topography is taken with respect to a reference plane, see Sect. 2.1, the additional ice volume between this plane and the deformed ground must be considered as an additional load.

The stratification of the ground model consists of an elastic crust of thickness $H_{\mathrm{c}}$, an elastic mantle lithosphere of thickness $H_{\mathrm{ml}}$ (which, together, form the rheological lithosphere of thickness $\left.H_{1}=H_{\mathrm{c}}+H_{\mathrm{ml}}\right)$ and a viscoelastic upper mantle below the lithosphere. The parameter values used for the ground model are given in Table 2 (Sohl and Spohn 1997, Spohn et al. 1998). Note that the lithosphere layers are treated as elastic $\left(\eta_{\mathrm{c}}=\eta_{\mathrm{ml}}=\infty\right)$, whereas the upper mantle below the mantle lithosphere is treated as incompressible $\left(\kappa_{\mathrm{um}}=\infty\right)$ in order to keep the viscoelastic fluid stable (Klemann et al. 2003).

The most crucial parameter of the lithosphere/mantle system, the lithosphere thickness $H_{1}$, is varied between 50 and $400 \mathrm{~km}$. These values cover the range of thicknesses discussed in the literature (Spohn et al. 1998, Johnson et al. 2000, Zuber et al. 2000). 


\begin{tabular}{lll}
\hline Layer & Parameter & Value \\
\hline Crust & Density, $\rho_{\mathrm{c}}$ & $2900 \mathrm{~kg} \mathrm{~m}^{-3}$ \\
& Thickness, $H_{\mathrm{c}}$ & $40 \mathrm{~km}$ \\
& Bulk modulus, $\kappa_{\mathrm{c}}$ & $106.4 \mathrm{GPa}$ \\
& Shear modulus, $\mu_{\mathrm{c}}$ & $44.8 \mathrm{GPa}$ \\
& Viscosity, $\eta_{\mathrm{c}}$ & $\infty$ \\
Mantle lithosphere & Density, $\rho_{\mathrm{ml}}$ & $3500 \mathrm{~kg} \mathrm{~m}^{-3}$ \\
& Thickness, $H_{\mathrm{ml}}$ & $10 \ldots 360 \mathrm{~km}$ \\
& Bulk modulus, $\kappa_{\mathrm{ml}}$ & $136.3 \mathrm{GPa}$ \\
& Shear modulus, $\mu_{\mathrm{ml}}$ & $74 \mathrm{GPa}$ \\
Upper mantle below & Viscosity, $\eta_{\mathrm{ml}}$ & $\infty$ \\
& Density, $\rho_{\mathrm{um}}$ & $3500 \mathrm{~kg} \mathrm{~m}^{-3}$ \\
& Thickness, $H_{\mathrm{um}}$ & $\infty$ \\
& Bulk modulus, $\kappa_{\mathrm{um}}$ & $\infty$ \\
& Shear modulus, $\mu_{\mathrm{um}}$ & $145 \mathrm{GPa}^{21} \mathrm{Pas}$ \\
\hline
\end{tabular}

Table 2: Values of the physical parameters used for the ground model.

\section{Model input}

\subsection{Topography}

In the absence of any ice load, the isostatically equilibrated ground is approximated by a parabolic bowl,

$$
z=b_{0}(r)=b_{0}^{90 \mathrm{~N}}+\left(b_{0}^{30 \mathrm{~N}}-b_{0}^{90 \mathrm{~N}}\right) \frac{r^{2}}{R_{\mathrm{b}}^{2}},
$$

where $z$ is positive upward and equal to zero for the reference geoid, $r$ the distance from the north pole $\left(90^{\circ} \mathrm{N}\right)$ in the horizontal plane, $b_{0}^{90 \mathrm{~N}}=-5 \mathrm{~km}$ the elevation of the equilibrated ground at the pole, $b_{0}^{30 \mathrm{~N}}=-2 \mathrm{~km}$ the elevation of the equilibrated ground at $30^{\circ} \mathrm{N}$, and $R_{\mathrm{b}}=3556.28 \mathrm{~km}$ the distance from the pole to $30^{\circ} \mathrm{N}$ (Greve 2000a). The bowl approximates the MOLA data by Zuber et al. (1998) and is assumed to hold also below the NPC. The actual ground position, $z=b(r, t)$, then follows from $b=b_{0}-w$, where $w$ is the vertical surface displacement of the lithosphere (positive downward) due to glacial loading. The ice thickness above the equilibrated ground, $H^{\star}(r, t)$, is described as a paraboloid-like cap,

$$
H^{\star}(r, t)=H_{\mathrm{i}}(t)\left(1-\left(\frac{r}{R_{\mathrm{i}}(t)}\right)^{4 / 3}\right), \quad \text { for } r<R_{\mathrm{i}}(t),
$$

where the radius of the NPC varies harmonically in time, $t$,

$$
R_{\mathrm{i}}(t)=\frac{R_{\mathrm{i}}^{0}+R_{\mathrm{i}}^{\max }}{2}-\frac{R_{\mathrm{i}}^{\max }-R_{\mathrm{i}}^{0}}{2} \cos \frac{2 \pi t}{t_{\mathrm{obl}}}
$$


between the present $(t=0)$ minimum, $R_{\mathrm{i}}^{0}=564.19 \mathrm{~km}$, and the past maximum, $R_{\mathrm{i}}^{\max }=$ $889.07 \mathrm{~km}$. These values correspond to southward extents of the NPC to $80.5^{\circ} \mathrm{N}$ and $75^{\circ} \mathrm{N}$, respectively. The symbol $t_{\mathrm{obl}}=1.3 \mathrm{Myr}$ denotes the period of the first modulation of the obliquity cycle, which was found to be the most likely period for significant climate-induced changes of the ice extent in the geologically recent past (Greve 2000a; Figs. 1, 2).

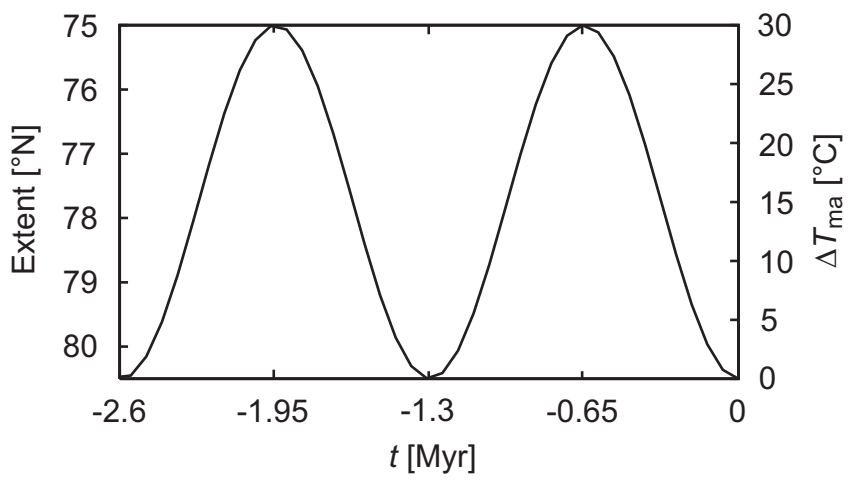

Figure 2: Simulation forcing: Ice extent and deviation of actual surface temperature from present surface temperature (same curve) over two 1.3 Myr obliquity cycles according to Eqs. (8) and (12).

The maximum thickness, $H_{\mathrm{i}}(t)$, is calculated with the present value, $H_{\mathrm{i}}^{0}=3 \mathrm{~km}$, and the assumption that

$$
\frac{H_{\mathrm{i}}^{2}(t)}{R_{\mathrm{i}}(t)}=\text { const }
$$

which holds exactly for a perfectly plastic circular ice sheet on a rigid horizontal base (Paterson 1994). We thus obtain

$$
H_{\mathrm{i}}(t)=H_{\mathrm{i}}^{0}\left(\frac{R_{\mathrm{i}}(t)}{R_{\mathrm{i}}^{0}}\right)^{1 / 2} .
$$

For the maximum radius assumed for the past, $R_{\mathrm{i}}(t)=R_{\mathrm{i}}^{\max }$, this yields a maximum thickness of $H_{\mathrm{i}}^{\max }=3.766 \mathrm{~km}$. In contrast, Greve (2000a) applied the ad-hoc assumption $H_{\mathrm{i}}(t) / R_{\mathrm{i}}(t)=$ const, which corresponds to the larger value of $H_{\mathrm{i}}^{\max }=4.728 \mathrm{~km}$.

The simple representation of the topography by Eqs. (6)-(10) means that small- and medium-scale features of the present NPC like the $500 \mathrm{~km}$ long chasm and the spiraling troughs (Thomas et al., 1992) are not accounted for. While these features are interesting and their origin is poorly understood, they are beyond the scope of this study which is the investigation of very basic, large-scale properties of the NPC and the underlying ground only. 


\subsection{Surface temperature}

Following Greve (2000a) and references therein, we parameterize the present mean annual air temperature at the surface of the NPC, $T_{\text {ma }}$, as a linear function depending on colatitude, $\tilde{\phi}\left(\tilde{\phi}=90^{\circ} \mathrm{N}-\phi\right.$, where $\phi$ is the latitude), and elevation, $h$,

$$
T_{\mathrm{ma}}^{\mathrm{present}}(\tilde{\phi}, h)=T_{\mathrm{ma}}^{0}+\gamma_{\mathrm{ma}} h+c_{\mathrm{ma}} \tilde{\phi}
$$

with the constants $T_{\mathrm{ma}}^{0}=-105^{\circ} \mathrm{C}, \gamma_{\mathrm{ma}}=-2.5^{\circ} \mathrm{C} / \mathrm{km}$ (mean lapse rate), and $c_{\mathrm{ma}}=$ $1.5^{\circ} \mathrm{C} /{ }^{\circ}$ lat. The difference from present conditions is described by the time-dependent offset

$$
\Delta T_{\mathrm{ma}}(t)=\frac{\Delta T_{\mathrm{ma}}^{\mathrm{max}}}{2}\left(1-\cos \frac{2 \pi t}{t_{\mathrm{obl}}}\right)
$$

which varies with the same obliquity period of $t_{\mathrm{obl}}=1.3 \mathrm{Myr}$ as the ice extent and thickness (see above) and has a maximum of $\Delta T_{\mathrm{ma}}^{\max }=30^{\circ} \mathrm{C}$ for periods of large obliquity (Fig. 2). Consequently, the space- and time-dependent surface-temperature forcing is

$$
T_{\mathrm{ma}}(\tilde{\phi}, h, t)=T_{\mathrm{ma}}^{\mathrm{present}}(\tilde{\phi}, h)+\Delta T_{\mathrm{ma}}(t)
$$

According to Eqs. (8), (10) and (12), minimum temperature corresponds to minimum ice volume and maximum temperature to maximum ice volume. The idea behind this somewhat counter-intuitive correlation (at least for terrestrial glaciologists) is that increasing air temperature entails increasing humidity and therefore a larger potential for precipitation, which builds up the NPC. On Earth, this effect is over-compensated by increased surface melting, which, however, is not relevant for the recent climate history of Mars due to the low temperatures. On Mars, ablation at the surface of the NPC is mainly due to sublimation of water ice into the atmosphere. Jakosky et al. (1993) modelled this process and found a strong increase of sublimation with increasing obliquity/surface temperature. This works against the increasing precipitation, and therefore the net effect on the surface mass balance is not clear from the outset. The reason to assume a positive correlation between surface temperature and ice volume is that otherwise the ice volume would be maximal at present, which does not agree with a larger extent south to $75^{\circ} \mathrm{N}$ in the past. Temperature and ice volume are assumed to follow the first modulation (period of $t_{\mathrm{obl}}=1.3 \mathrm{Myr}$ ) of the obliquity cycle, which is currently close to its minimum (Ward 1992), in phase, so that both quantities are minimal at present (Greve 2000a).

Touma and Wisdom (1993) and Laskar et al. (2002) pointed out that the obliquity, which, as mentioned above, currently oscillates with periods of $125 \mathrm{kyr}$ and $1.3 \mathrm{Myr}$ between ca. $15^{\circ}$ and $35^{\circ}$ around the average of $25^{\circ}$, probably underwent a transition about 
4 Myr ago, with a ca. $10^{\circ}$ larger average obliquity before that time. Since this shift must have been associated with a significant shift in the climatic conditions which is not reflected by our scenario of temperature and ice volume, we restrict our study to the period from 2.6 Myr ago until the present, that is, the two most recent long obliquity cycles.

Of course, the response of the climate system to harmonic orbital forcing is not necessarily harmonic due to the nonlinear nature of the system. Therefore, the assumed harmonic temperature and ice-volume variations described by Eqs. (8), (10) and (12) are only an approximation owing to the lack of better knowledge about the generation of higher-frequency responses of the climate system. Again, considering the very fundamental objective of this study, this is not a severe problem.

\subsection{Geothermal heat flux}

The geothermal heat flux at the top of the crust in the north polar region, $q_{\mathrm{geo}}^{\mathrm{s}}$, is a crucial parameter for the ice flow, because it largely controls the temperature field in the lower parts of the NPC. Via the exponentially temperature-dependent flow-rate factor $A\left(T^{\prime}\right)$ in Eq. (1), this has a pronounced effect on the ice viscosity and therefore on the flow velocity. Here, we vary the geothermal heat flux between 10 and $50 \mathrm{~mW} \mathrm{~m}^{-2}$. This is based on published estimates based on models of the Martian interior (e.g., Solomon and Head 1990, Schubert et al. 1992, Sohl and Spohn 1997, Wüllner and Harder 1998).

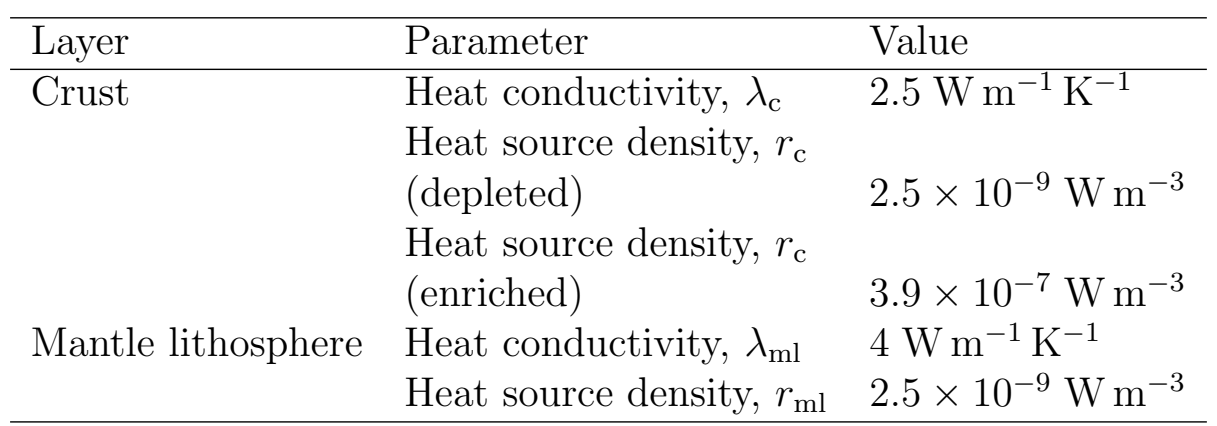

Table 3: Values of the physical parameters for the geothermal heat flux model.

With some further assumptions, the geothermal heat flux can be related to the thickness of the rheological lithosphere, $H_{1}$. To this end, we use the parameter values of Table 3 . The given values for the heat conductivities of the crust and the mantle lithosphere, $\lambda_{\mathrm{c}}$ and $\lambda_{\mathrm{ml}}$, respectively, are based on results by Solomon and Head (1990). The range of heat source densities, $r_{\mathrm{c}}$ and $r_{\mathrm{ml}}$, is by Wüllner and Harder (1998). As for $r_{\mathrm{c}}$, these authors assume an old southern-hemispheric crust formed by differentiation of an early mantle and therefore enriched by radiogenic isotopes, and, in contrast, a younger northern-hemispheric crust formed by a depleted mantle (see also Breuer et al. 1993). Consequently, the depleted 
crust is more likely for the region of the NPC. Nevertheless, we consider both values as limits of a possible range.

The mean temperature at the top of the crust is set to $T_{\mathrm{s}}=193 \mathrm{~K}\left(-80^{\circ} \mathrm{C}\right)$. To assess the base of the rheological lithosphere, we use the proposed isotherm $T_{1}=0.6 \times T_{\text {melt }}$ (Meissner and Vetter 1979). The melting temperature of the upper-mantle material, $T_{\text {melt }}$, at the depth $H_{1}$ is computed according to terrestrial conditions by

$$
\begin{aligned}
p[\mathrm{GPa}]= & \frac{T_{\text {melt }}[\mathrm{K}]-1373}{136} \\
& +4.968 \times 10^{-4} \exp \left[1.2 \times 10^{-2}\left(T_{\text {melt }}[\mathrm{K}]-1373\right)\right]
\end{aligned}
$$

(McKenzie and Bickle 1988), where $p=\rho_{\mathrm{c}} g H_{\mathrm{c}}+\rho_{\mathrm{ml}} g H_{\mathrm{ml}}$ is the hydrostatic pressure at the base of the lithosphere (see Table 2).

Let $\tilde{z}$ be the vertical coordinate, positive downward and equal to zero at the top of the crust (this is different from the definition of $z$ in Sect. 3.1). Then, in the crust,

$$
q_{\mathrm{geo}}(\tilde{z})=q_{\mathrm{geo}}^{\mathrm{s}}-r_{\mathrm{c}} \tilde{z}=\lambda_{\mathrm{c}} \frac{\partial T}{\partial \tilde{z}}
$$

so that

$$
T(\tilde{z})=T_{\mathrm{s}}+\frac{q_{\mathrm{geo}}^{\mathrm{s}}}{\lambda_{\mathrm{c}}} \tilde{z}-\frac{r_{\mathrm{c}}}{2 \lambda_{\mathrm{c}}} \tilde{z}^{2}
$$

In an analogous way, in the mantle lithosphere,

$$
q_{\text {geo }}(\tilde{z})=q_{\text {geo }}^{\mathrm{c} / \mathrm{m}}-r_{\mathrm{ml}}\left(\tilde{z}-H_{\mathrm{c}}\right)=\lambda_{\mathrm{ml}} \frac{\partial T}{\partial \tilde{z}}
$$

(the index "c/m" refers to the crust/mantle boundary at the depth $\tilde{z}=H_{\mathrm{c}}$ ), which yields with Eqs. (15) and (16)

$$
\begin{aligned}
T(\tilde{z}) & =T_{\mathrm{c} / \mathrm{m}}+\frac{q_{\mathrm{geo}}^{\mathrm{c} / \mathrm{m}}}{\lambda_{\mathrm{ml}}}\left(\tilde{z}-H_{\mathrm{c}}\right)-\frac{r_{\mathrm{ml}}}{2 \lambda_{\mathrm{ml}}}\left(\tilde{z}-H_{\mathrm{c}}\right)^{2} \\
& =T_{\mathrm{s}}+\frac{q_{\mathrm{geo}}^{\mathrm{s}}}{\lambda_{\mathrm{c}}} H_{\mathrm{c}}-\frac{r_{\mathrm{c}}}{2 \lambda_{\mathrm{c}}} H_{\mathrm{c}}^{2}+\frac{q_{\mathrm{geo}}^{\mathrm{s}}-r_{\mathrm{c}} H_{\mathrm{c}}}{\lambda_{\mathrm{ml}}}\left(\tilde{z}-H_{\mathrm{c}}\right)-\frac{r_{\mathrm{ml}}}{2 \lambda_{\mathrm{ml}}}\left(\tilde{z}-H_{\mathrm{c}}\right)^{2} .
\end{aligned}
$$

This temperature profile holds for the entire thermal lithosphere in which heat transport is controlled by conduction. The above definition of the base of the rheological lithosphere corresponds to the condition

$$
T\left(\tilde{z}=H_{1}\right)=T_{1} .
$$


Inserting this into Eq. (18) gives

$$
\begin{aligned}
T_{1}= & T_{\mathrm{s}}+q_{\mathrm{geo}}^{\mathrm{s}}\left(\frac{H_{\mathrm{c}}}{\lambda_{\mathrm{c}}}+\frac{H_{\mathrm{l}}-H_{\mathrm{c}}}{\lambda_{\mathrm{ml}}}\right) \\
& -\frac{r_{\mathrm{c}} H_{\mathrm{c}}\left(H_{\mathrm{l}}-H_{\mathrm{c}}\right)}{\lambda_{\mathrm{ml}}}-\frac{r_{\mathrm{ml}}\left(H_{\mathrm{l}}-H_{\mathrm{c}}\right)^{2}}{2 \lambda_{\mathrm{ml}}}-\frac{r_{\mathrm{c}} H_{\mathrm{c}}^{2}}{2 \lambda_{\mathrm{c}}}
\end{aligned}
$$

or, solved for $q_{\mathrm{geo}}^{\mathrm{s}}$,

$$
\begin{aligned}
q_{\mathrm{geo}}^{\mathrm{s}}= & \left(T_{\mathrm{l}}-T_{\mathrm{s}}+\frac{r_{\mathrm{c}} H_{\mathrm{c}}\left(H_{\mathrm{l}}-H_{\mathrm{c}}\right)}{\lambda_{\mathrm{ml}}}+\frac{r_{\mathrm{ml}}\left(H_{\mathrm{l}}-H_{\mathrm{c}}\right)^{2}}{2 \lambda_{\mathrm{ml}}}+\frac{r_{\mathrm{c}} H_{\mathrm{c}}^{2}}{2 \lambda_{\mathrm{c}}}\right) \\
& \times\left(\frac{H_{\mathrm{c}}}{\lambda_{\mathrm{c}}}+\frac{H_{\mathrm{l}}-H_{\mathrm{c}}}{\lambda_{\mathrm{ml}}}\right)^{-1} .
\end{aligned}
$$

This equation relates the geothermal heat flux at the top of the crust to the thickness of the rheological lithosphere. Results are shown in Fig. 3 for the depleted and the enriched crust. Evidently, $q_{\text {geo }}^{\mathrm{s}}$ decreases with increasing $H_{1}$, and the assumed interval $H_{1}=50 \ldots 400 \mathrm{~km}$ corresponds approximately to $q_{\text {geo }}^{\mathrm{s}}=45 \ldots 10 \mathrm{~mW} \mathrm{~m}^{-2}$. However, since the above parameter values required to derive this relation are rather uncertain, we only use it as an additional confirmation for the consistency of our investigated ranges $H_{1}=50 \ldots 400 \mathrm{~km}$, $q_{\text {geo }}^{\mathrm{s}}=10 \ldots 50 \mathrm{~mW} \mathrm{~m}^{-2}$ and consider these two quantities as independent in the following.

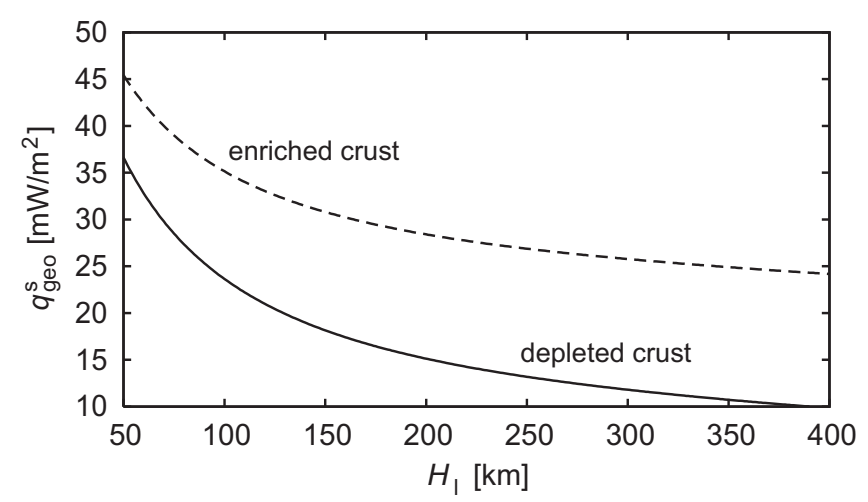

Figure 3: Computed geothermal heat flux at the top of the crust, $q_{\text {geo }}^{\mathrm{s}}$, as a function of lithosphere thickness, $H_{1}$, for heat source densities of a depleted (northern-hemisphere type) and an enriched (southern-hemisphere type) crust due to relation (21). 


\section{Discussion of simulations}

\subsection{Simulation set-up}

For this study, a series of simulations with varied lithosphere thickness and geothermal heat flux was carried out. The model time for the simulations runs from $t=-2.6 \mathrm{Myr}=-2 t_{\mathrm{obl}}$ until $t=0$ (present). Thus, two long obliquity cycles are covered. This guarantees that during the last cycle (on which we focus our attention) the results are independent of any arbitrary initial conditions. The time-dependent forcings of topography, surface temperature and geothermal heat flux are those described in Sect. 3. For the thickness of the rheological lithosphere, $H_{1}$, the values $50,100,150, \ldots, 400 \mathrm{~km}$ are used, and the geothermal heat flux, $q_{\text {geo }}^{\mathrm{s}}$, is varied over the range $10,15,20, \ldots, 50 \mathrm{~mW} \mathrm{~m}^{-2}$.

\subsection{Results}

First, we assess the possible effect of viscoelasticity of the ground. Figure 4 shows the relaxation time of the three-layer lithosphere/mantle system, $\tau$, as a function of the normalized Hankel wave number of the ice load, $k R_{\mathrm{m}}$ (where $R_{\mathrm{m}}=3397 \mathrm{~km}$ is the mean Martian radius), for different values of $H_{1}$. Two different modes appear: the buoyancy mode M0, which is mainly responsible for the vertical lithosphere displacement and the associated gravity signal, and the viscoelastic mode L0 with much smaller amplitudes (Wu and Peltier 1982, Wolf 1985a). For both modes and all values of $H_{1}$, the relaxation times, $\tau$, are always smaller than $30 \mathrm{kyr}\left(1 / 40\right.$ of the obliquity period) for $k R_{\mathrm{m}} \sim 10 \ldots 20$ (approximately corresponding to the wavelengths of the ice load at maximum and minimum extent, respectively). Therefore, the lithosphere/mantle system follows the slowly varying ice load in a quasi-static fashion, which means that the finite viscosity of the upper mantle does not affect the dynamics of the system, and the material can be replaced by an inviscid fluid (what is done in our computations of lithosphere displacements). Of course, this result depends on the viscosity value assumed for the upper mantle. If it were larger than the terrestrial value of $10^{21} \mathrm{Pas}$ (Table 2 ) by at least an order of magnitude, the relaxation times would increase correspondingly and invalidate this reasoning. However, $10^{21} \mathrm{Pas}$ has turned out to be more like an upper bound for the dynamic viscosity in convection models recently discussed for Mars (e.g., Parmentier and Grasset 1998). Therefore, modelling the mantle as an inviscid fluid is justified.

By employing a similar viscoelastic lithosphere/mantle model, Johnson et al. (2000) report a relaxation time of $100 \mathrm{kyr}$ for isostatic compensation, which they misleadingly named "Maxwell time". It is not completely clear how this figure was obtained. In

\footnotetext{
${ }^{1}$ The Maxwell time describes the relaxation of shear stress and is the ratio of viscosity and shear
} 


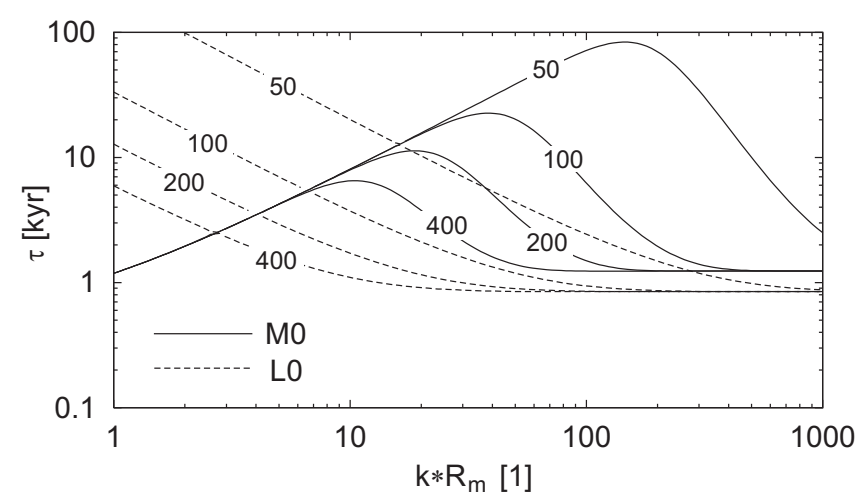

Figure 4: Relaxation time, $\tau$, as a function of Hankel wave number of the ice load, $k$, normalized with respect to the mean Martian radius, $R_{\mathrm{m}}$, for modes M0, L0 and lithosphere thicknesses of $H_{1}=50 \mathrm{~km}, 100 \mathrm{~km}, 200 \mathrm{~km}, 400 \mathrm{~km}$ (labels on the lines).

any case, their Fig. 8 shows that relaxation times, understood like here as times required for reaching a fraction $(1-1 / e) \approx 63 \%$ of steady-state compensation, are $\leq 40 \mathrm{kyr}$ for lithosphere thicknesses of 50-100 km and loads comparable in wavelength to the NPC, which agrees well with our findings.

In order to compare the isostatic responses of the different simulations, we define the fraction of isostatic compensation,

$$
f_{\text {iso }}=\frac{w}{H \rho_{\mathrm{i}} / \rho_{\text {um }}},
$$

which relates the actual surface displacement, $w$, to full isostatic compensation, which is local ice thickness, $H$, times the density ratio of ice and upper mantle, $\rho_{\mathrm{i}} / \rho_{\text {um }}$. Fig. 5 shows $f_{\text {iso }}$ for the centre of the NPC (north pole) and the two time slices $t=0$ (present, minimum ice extent and thickness) and $t=-650 \mathrm{kyr}$ (half a cycle ago, maximum ice extent and thickness). Since, for our prescribed-topography scenarios, $f_{\text {iso }}$ does not depend on $q_{\text {geo }}^{\mathrm{s}}$, it is plotted only against $H_{1}$.

It is evident that $f_{\text {iso }}$ decreases strongly with increasing $H_{1}$, for the present NPC (minimum extent) from more than 0.8 to less than 0.2 for the considered range of values of $H_{1}$. Of course, this is so because the flexural rigidity of the elastic lithosphere becomes larger for larger values of $H_{1}$ (in the thin-plate approximation with the third power). In the range $H_{1} \leq 200 \mathrm{~km}$ investigated by Johnson et al. (2000), very similar results were reported by them (their Fig. 5). For the past NPC (maximum extent), the trend is the same, but $f_{\text {iso }}$ is generally somewhat larger. As we will discuss below in more detail, this behaviour has a distinct impact on the ice dynamics. The larger $H_{1}$, the smaller the lithospheric deflection, modulus, $\eta_{\mathrm{um}} / \mu_{\mathrm{um}}$ [see Eq. (4)], which is $218.5 \mathrm{yr}$ for our values (Table 2) and 316.9 yr for those of Johnson et al. (2000). 


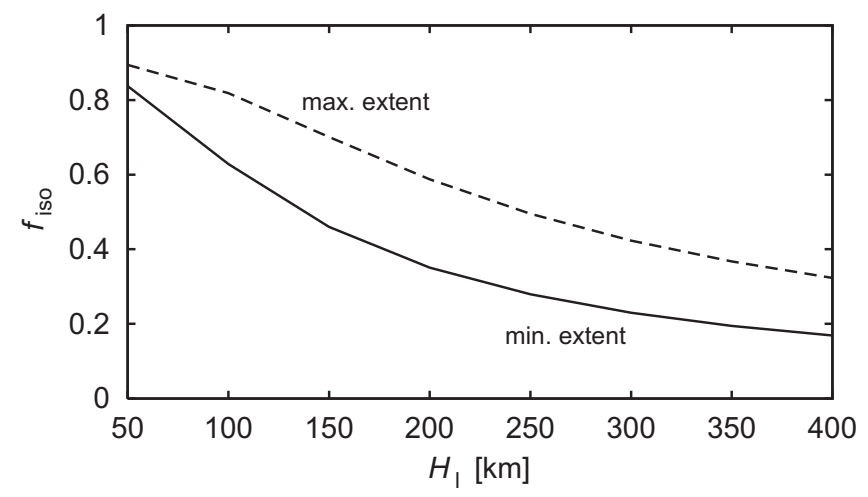

Figure 5: Computed fraction of isostatic compensation, $f_{\text {iso }}$, for the centre of the NPC (north pole) as a function of lithosphere thickness, $H_{1}$, for minimum ice extent at present and maximum ice extent at $t=-650 \mathrm{kyr}$.

the thinner the NPC for given surface topography, the slower the ice flow and the smaller the accumulation and ablation rates.

We will see below that the simulation with $H_{1}=100 \mathrm{~km}, q_{\text {geo }}^{\mathrm{s}}=25 \mathrm{~mW} \mathrm{~m}^{-2}$ is a probable scenario under the assumptions of this study. Therefore, this simulation shall now be discussed exemplarily in some detail. Figures 6 and 7 show the ice and lithosphere surfaces, the velocity and temperature fields and the surface velocities and accumulation-ablation rates for cross-sections across the centre (north pole) of the NPC and present and past $(t=-650 \mathrm{kyr})$ conditions, respectively. A distinct lithosphere depression can be recognized. At the centre, it reaches $63 \%$ of full isostatic compensation for the present volume minimum and $82 \%$ for the past maximum (see also Fig. 5). The flow field shows the typical downward-and-outward pattern for a grounded ice body and reaches maximum surface velocities, $v_{\mathrm{s}, \max }$, of $2.96 \mathrm{~mm} \mathrm{yr}^{-1}$ at present and $66.5 \mathrm{~mm} \mathrm{\textrm {yr } ^ { - 1 }}$ in the past. Correspondingly, the maximum accumulation rates, $S_{\max }$, and ablation rates, $M_{\max }$, are $0.13 \mathrm{~mm}$ w.e. $\mathrm{yr}^{-1}$ and $0.11 \mathrm{~mm}$ w.e. $\mathrm{yr}^{-1}$, resp., for the present, compared to $2.57 \mathrm{~mm}$ w.e. $\mathrm{yr}^{-1}$ and $0.41 \mathrm{~mm}$ w.e. $\mathrm{yr}^{-1}$, resp., in the past. These large differences, which occur periodically over the obliquity cycles due to varying ice volume and surface temperature, reflect the "stop-and-go-type dynamics" of the NPC, a behaviour that has already been described by Greve (2000a).

In sharp contrast to the advection-controlled temperature fields of terrestrial ice sheets, the temperature field of the Martian NPC is mainly controlled by heat conduction, so that the temperature increases regularly with depth with a gradient determined by the geothermal heat flux. This is a direct consequence of the very small flow velocities. The maximum basal temperature relative to pressure melting is $-61.4^{\circ} \mathrm{C}$ at present and $-40.6^{\circ} \mathrm{C}$ in the past.

Figure 8 displays the computed present values of $S_{\max }$ and $M_{\max }$ for the parameter 

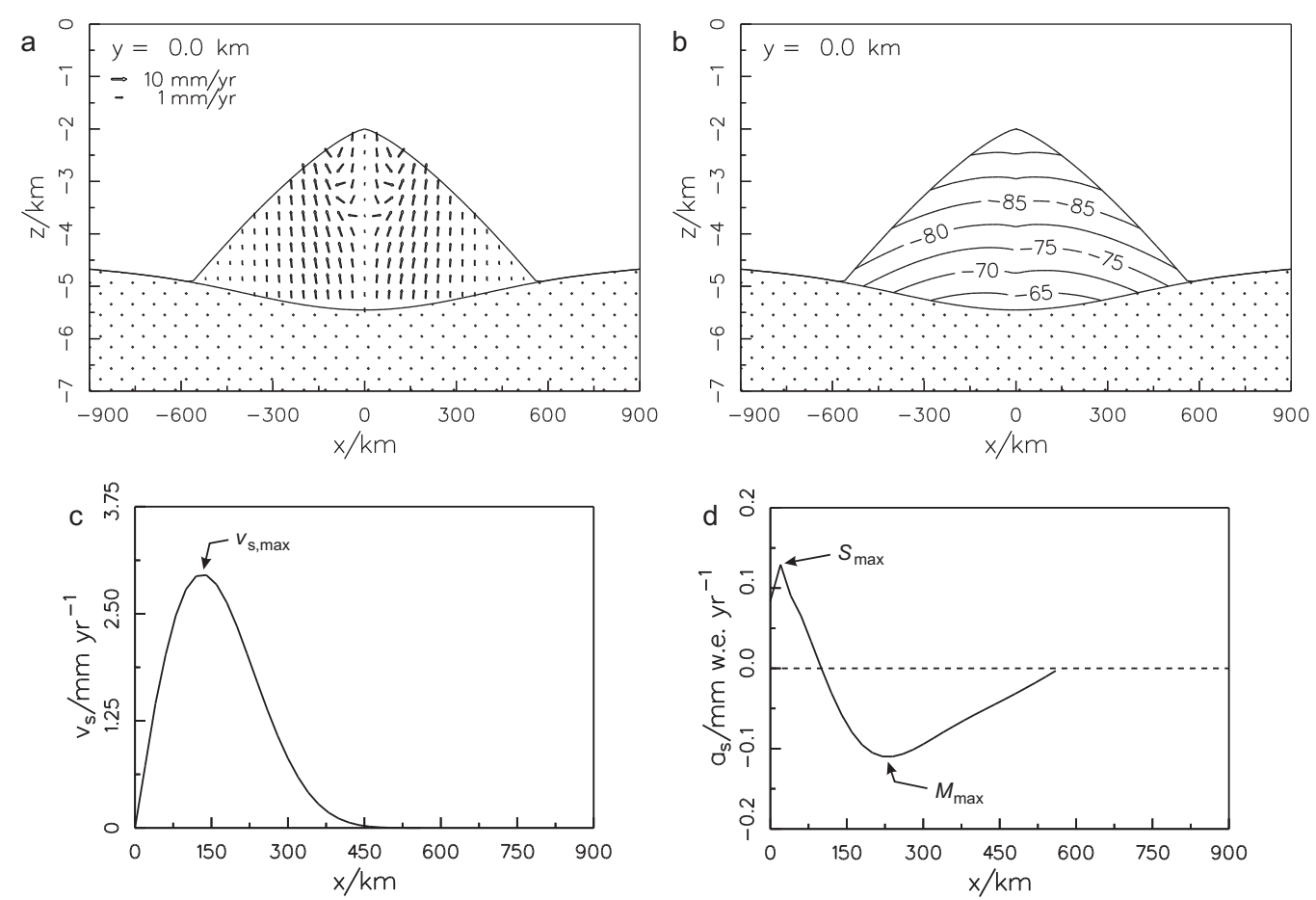

Figure 6: Simulation with parameters $H_{\mathrm{l}}=100 \mathrm{~km}, q_{\mathrm{geo}}^{\mathrm{s}}=25 \mathrm{~mW} \mathrm{~m}^{-2}$; minimum extent at present. (a) flow-velocity field, (b) temperature field (relative to pressure melting, in $\left.{ }^{\circ} \mathrm{C}\right)$ for a cross-section across the north pole $(x, y)=(0,0)(x, y$ span the horizontal plane). (c) surface velocity, (d) accumulation-ablation rate for a flowline from the north pole $(x, y)=(0,0)$ to the margin. Maximum values $v_{\mathrm{s}, \max }, S_{\max }$ and $M_{\max }$ are indicated.

space of $H_{1}$ and $q_{\text {geo }}^{\mathrm{s}}$. Both values increase with decreasing $H_{1}$ (enhanced ice flow due to increased ice thickness) and increasing $q_{\text {geo }}^{\mathrm{s}}$ (enhanced ice flow due to increased ice temperature). $S_{\max }$ and $M_{\max }$ vary between almost $10 \mathrm{~mm}$ w.e. $\mathrm{yr}^{-1}$ and zero; the reason for $S_{\max }$ becoming zero for some of the simulations with $q_{\text {geo }}^{\mathrm{s}} \leq 20 \mathrm{~mW} \mathrm{~m}^{-2}$ is that the simulated ice flow is so slow in these cases that the whole surface of the NPC, which was larger in the past [Eq. (8), Fig. 2], has a negative mass balance. Greve (2000a) extensively discussed the problem of independent estimates of these quantities mainly from atmospheric considerations and argued that, despite large uncertainties, the order of $0.1 \mathrm{~mm}$ w.e. $\mathrm{yr}^{-1}$ is a likely range. ${ }^{2}$ Following this reasoning, we define an interval varying by a factor of ten around $0.1 \mathrm{~mm}$ w.e. $\mathrm{yr}^{-1}\left(0.1 / \sqrt{10} \ldots 0.1 \times \sqrt{10} \mathrm{~mm}\right.$ w.e. $\left.\mathrm{yr}^{-1}\right)$ as the target range for the computed present values of $S_{\max }$ and $M_{\max }$ (shaded areas in Fig. 8). Evidently, the resulting limitations for possible combinations of $H_{1}$ and $q_{\text {geo }}^{\mathrm{s}}$ are

\footnotetext{
${ }^{2}$ This value can be made plausible as follows: The mean water-vapour abundance in the atmosphere of Mars is of the order of 10 precipitable micrometers, compared to some centimeters on Earth (Jakosky and Haberle 1992). If we assume that this ratio $(\sim 1 / 3000)$ transfers to accumulation/ablation rates and use the terrestrial Greenland ice sheet with on average $\sim 300 \mathrm{~mm}$ w.e. $\mathrm{yr}^{-1}$ for comparison, we obtain $\sim 0.1 \mathrm{~mm}$ w.e. $\mathrm{yr}^{-1}$ for the Martian NPC.
} 

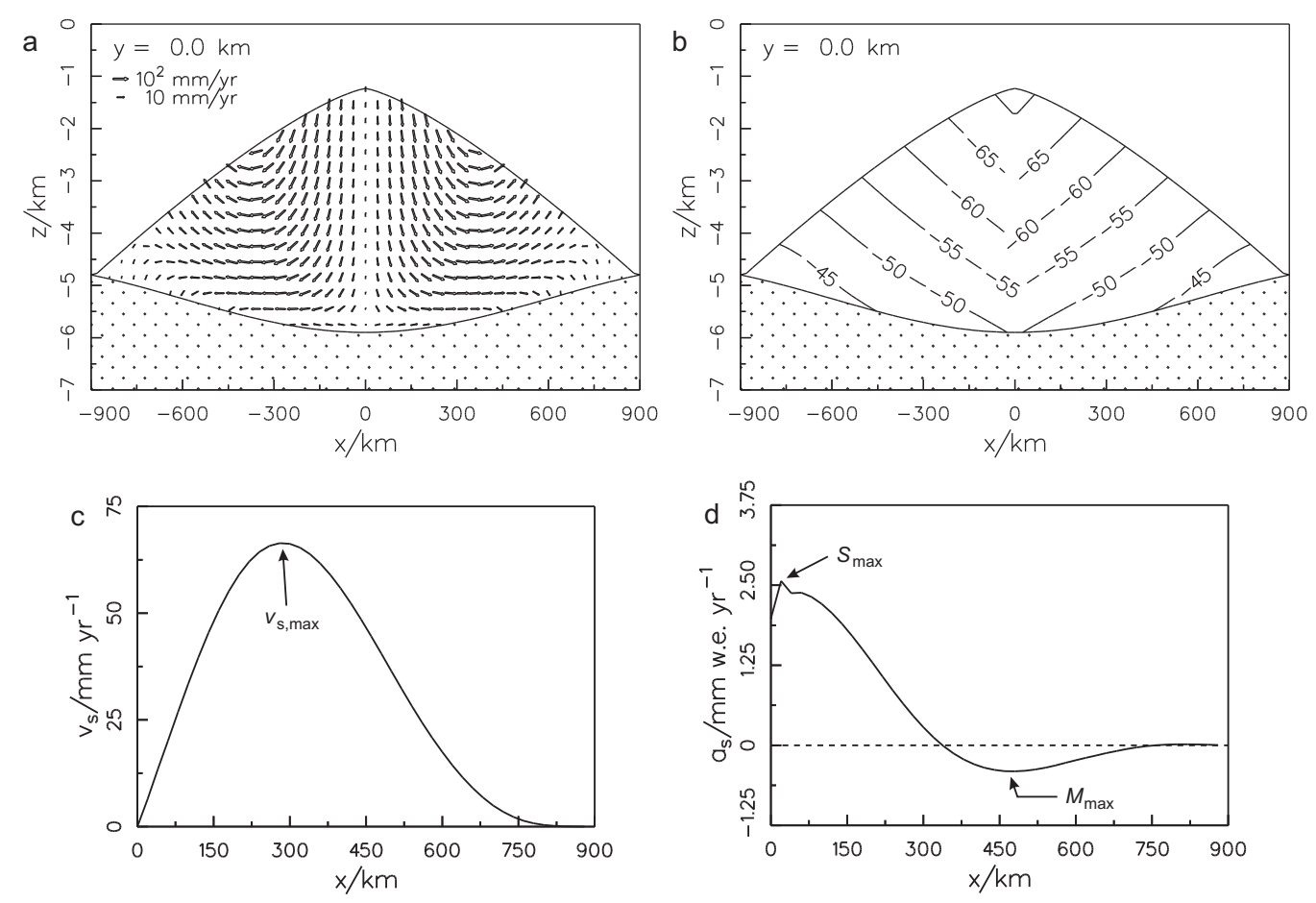

Figure 7: Simulation with parameters $H_{\mathrm{l}}=100 \mathrm{~km}, q_{\text {geo }}^{\mathrm{s}}=25 \mathrm{~mW} \mathrm{~m}^{-2}$; maximum extent at $t=-650 \mathrm{kyr}$. (a) flow-velocity field, (b) temperature field (relative to pressure melting, in ${ }^{\circ} \mathrm{C}$ ) for a cross-section across the north pole $(x, y)=(0,0)(x, y$ span the horizontal plane). (c) surface velocity, (d) accumulation-ablation rate for a flowline from the north pole $(x, y)=(0,0)$ to the margin. Maximum values $v_{\mathrm{s}, \max }, S_{\max }$ and $M_{\max }$ are indicated.

stronger due to the target range of $S_{\max }$ than due to that of $M_{\max }$, and the intersection of both target ranges is essentially equal to that of $S_{\max }$. Since this intersection covers all considered values of $H_{1}$, a constraint on $H_{1}$ does not arise. However, possible values of $q_{\text {geo }}^{\mathrm{s}}$ are limited to the interval $15 \ldots 36 \mathrm{~mW} \mathrm{~m}^{-2}$.

By using the additional relation (Fig. 3) between $q_{\text {geo }}^{\mathrm{s}}$ and $H_{1}$ with the depleted crust, both quantities can be further constrained. The intersection of this relation with the target ranges of $S_{\max }$ and $M_{\max }$ yields rather small "allowed" intervals of ca. $H_{1}=80 \ldots 120 \mathrm{~km}$ and $q_{\text {geo }}^{\mathrm{s}}=20 \ldots 30 \mathrm{~mW} \mathrm{~m}^{-2}$. This justifies the parameters $H_{\mathrm{l}}=100 \mathrm{~km}, q_{\mathrm{geo}}^{\mathrm{s}}=$ $25 \mathrm{~mW} \mathrm{~m}^{-2}$ chosen for the exemplary simulation discussed above. However, it must be kept in mind that relation (21) depends on a number of parameters which can only be estimated roughly, so that these additional constraints of $q_{\text {geo }}^{\text {s }}$ and $H_{1}$ are fairly uncertain.

A lithosphere thickness of ca. $100 \mathrm{~km}$ and a low heat source density would agree well with the results from mantle differentiation modelling for the northern lowlands (Breuer et al. 1993). Thicknesses of less than $100 \mathrm{~km}$ have been suggested from analyses of MGS gravity and topography data (Johnson et al. 2000, Zuber et al. 2000). However, such estimates are based on topographic features formed in the distant past $(\geq 1000$ Myr before 

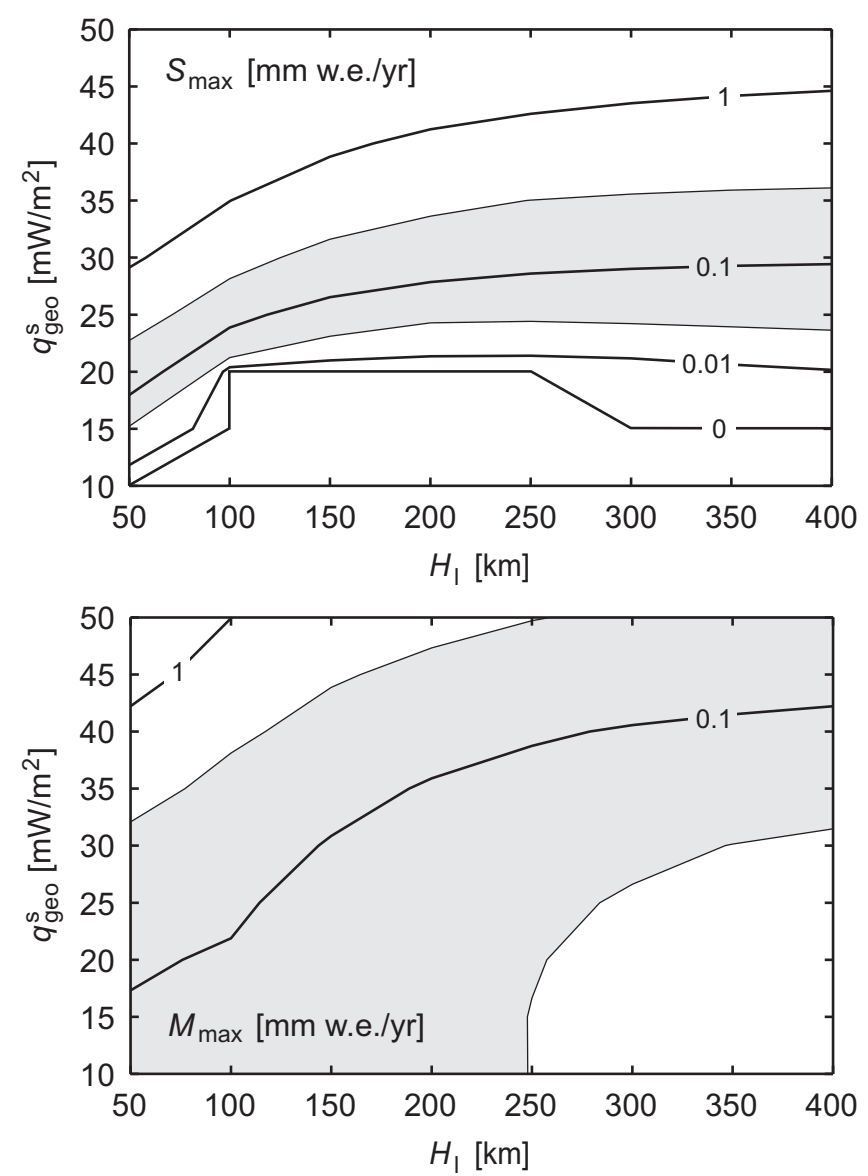

Figure 8: Computed maximum present accumulation and ablation rates at the ice surface, $S_{\max }$ and $M_{\max }$, as functions of lithosphere thickness, $H_{1}$, and geothermal heat flux, $q_{\text {geo }}^{\mathrm{s}}$. Shaded areas mark the target ranges of $\mathcal{O}\left(0.1 \mathrm{~mm}\right.$ w.e. $\left.\mathrm{yr}^{-1}\right)$.

present) and, thus, represent rheological conditions for higher subsurface temperatures than today and not the present state (Banerdt et al. 1992).

The parameter space of $H_{1}$ and $q_{\text {geo }}^{\mathrm{s}}$ yields a wide range of possible ice-flow velocities. Fig. 9 shows that the maximum surface velocity varies between $0.11 \mathrm{~mm} \mathrm{yr}^{-1}$ and $144 \mathrm{~mm} \mathrm{yr}^{-1}$, which includes everything between essentially stagnant and distinctly flowing ice. Restriction to the intersection of the target ranges of $S_{\max }$ and $M_{\max }$ narrows this range to the interval of $1 \ldots 5 \mathrm{~mm} \mathrm{yr}^{-1}$. This is four to five orders of magnitude smaller than the ice flow in the terrestrial ice sheets of Antarctica and Greenland (see also the above discussion of the stop-and-go-type dynamics).

For all simulations and all times, the basal temperatures are far below pressure melting. For the present, the maximum basal temperature reaches values between $-78^{\circ} \mathrm{C}$ and $-34^{\circ} \mathrm{C}$ and within the intersection of the target ranges of $S_{\max }$ and $M_{\max }$ it varies between $-70^{\circ} \mathrm{C}$ and $-55^{\circ} \mathrm{C}$ (Fig. 10; all values relative to pressure melting). This means that, provided the melting point of the material of the NPC is close to that of pure ice, it is very unlikely 


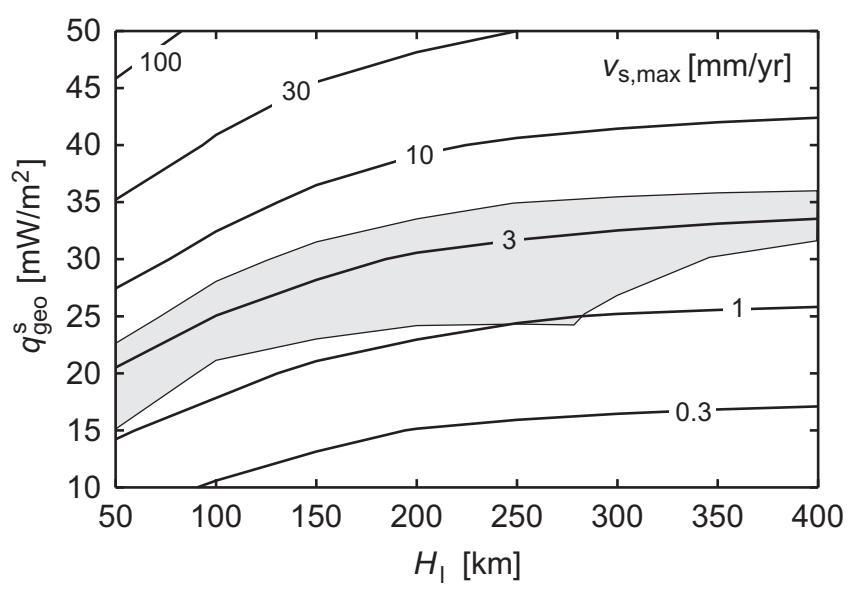

Figure 9: Computed maximum present flow velocity at the ice surface, $v_{\mathrm{s}, \max }$, as a function of lithosphere thickness, $H_{\mathrm{l}}$, and geothermal heat flux, $q_{\mathrm{geo}}^{\mathrm{s}}$. The shaded area marks the intersection of the target ranges of $S_{\max }$ and $M_{\max }$ (Fig. 8).

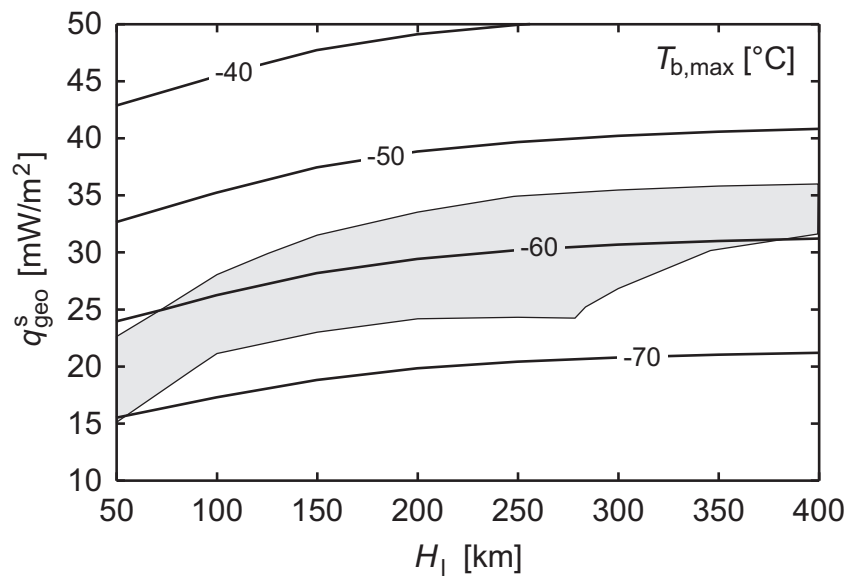

Figure 10: Computed maximum present basal ice temperature relative to pressure melting, $T_{\mathrm{b} \text {,max }}$, as a function of lithosphere thickness, $H_{1}$, and geothermal heat flux, $q_{\mathrm{geo}}^{\mathrm{s}}$. The shaded area marks the intersection of the target ranges of $S_{\max }$ and $M_{\max }$ (Fig. 8).

that liquid water is present at the base of the ice mass. However, recent investigations in Antarctica have shown that ponds of liquid water exist at temperatures down to $-50^{\circ} \mathrm{C}$ due to dissolved $\mathrm{CaCl}_{2}$, and some saline soils contain a few percent of liquid water down to even $-70^{\circ} \mathrm{C}$ (Wynn-Williams, pers. comm. 2000). Under comparable conditions, liquid water may thus be found at the base of the NPC despite the low temperatures, and, therefore, a chance remains that this region may serve as a potential habitat for lifeforms.

Greve (2000a) extensively discussed the sources of uncertainty for ice-flow simulations of the NPC, such as density, material behaviour and stiffening due to dust content. As already pointed out by Durham (1998), it was concluded that these factors [and also the possible occurrence of induced anisotropy of the ice grains, which may modify the isotropic 
flow law (1), see e.g. Svendsen and Hutter (1996)] are of secondary importance compared to the influence of uncertainties of the temperature field, which affects the ice flow via the exponentially temperature-dependent flow-rate factor $A\left(T^{\prime}\right)$ in Eq. (1). Apart from the surface temperature, the temperature field in the lower parts of the NPC (where most of the deformation takes place) is controlled by the geothermal heat flux and the heat conductivity of the NPC material. The uncertainty of the geothermal heat flux is assessed here by varying it over the range of plausible values. For the heat conductivity, we use the value for pure ice in terrestrial ice sheets (Table 1); however, it may be distinctly smaller due to mixed-in dust, which consequently would warm the lower parts of the NPC (Clifford 1987, Larsen and Dahl-Jensen 2000).

Therefore, the influence of dust content in the NPC is now assessed explicitly by repeating the above reference simulation with $H_{\mathrm{l}}=100 \mathrm{~km}, q_{\text {geo }}^{\mathrm{s}}=25 \mathrm{~mW} \mathrm{~m}^{-2}$ for dust volume fractions $\varphi=0.1,0.2$ and 0.5 . The density, $\rho$, and heat conductivity, $\lambda$, of the ice-dust mixture are computed as volume-fraction-weighed averages of the values for pure ice and crustal material, and the flow-enhancement (or for this application rather flow-obstruction) factor, $E$, in the flow law (1) is by Durham (1998), based on laboratory measurements of the deformation of ice-dust compounds:

$$
\begin{aligned}
\rho & =(1-\varphi) \rho_{\mathrm{i}}+\varphi \rho_{\mathrm{c}} \\
\lambda & =(1-\varphi) \lambda_{\mathrm{i}}+\varphi \lambda_{\mathrm{c}} \\
E & =e^{-2 \varphi}
\end{aligned}
$$

Results for present conditions and $\varphi=0 / 0.1 / 0.2 / 0.5$ are as follows: Maximum surface velocity $v_{\mathrm{s}, \max }=2.96 / 2.40 / 5.13 / 27.24 \mathrm{~mm} \mathrm{yr}^{-1}$, maximum accumulation rate $S_{\max }=$ $0.13 / 0.078 / 0.28 / 1.83 \mathrm{~mm}$ w.e. $\mathrm{yr}^{-1}$, maximum ablation rate $M_{\max }=0.11 / 0.13 / 0.17 /$ $0.52 \mathrm{~mm}$ w.e. $\mathrm{yr}^{-1}$, maximum basal temperature relative to pressure melting $T_{\mathrm{b}, \max }=$ $-61.4 /-58.8 /-56.5 /-51.5^{\circ} \mathrm{C}$. Basal warming due to decreasing heat conductivity is clearly visible, and leads to distinctly enhanced ice flow for $\varphi \geq 0.2$. By contrast, for $\varphi=0.1$ the direct stiffening effect described by Eq. (23c) predominates, so that in this case ice flow is reduced. Evidently, for $\varphi \leq 0.2$ (20\% dust content at maximum), $v_{\mathrm{s}, \max }$, $S_{\max }$ and $M_{\max }$ are within a factor two of their values for pure ice, and $T_{\mathrm{b}, \max }$ is altered by less than $5^{\circ} \mathrm{C}$, which can be regarded as an acceptable uncertainty range concerning the principle nature of our study. For a larger dust content of $\varphi>0.2$, a possibility which cannot be excluded at the present state of knowledge, the deviations increase quickly, so that our results would be largely invalidated under such circumstances.

As far as the uncertainty of the physical parameters for the ground model (Table 2) is concerned, the viscosity of the upper mantle does not affect our results as long as it is less 
than $10^{22}$ Pas (see discussion above). The system is most sensitive to variations of the lithosphere thickness, $H_{1}=H_{\mathrm{c}}+H_{\mathrm{ml}}$. This is because, in the thin-plate approximation, the flexural rigidity of the lithosphere, $K_{1}$, is given by

$$
K_{\mathrm{l}}=\frac{\mu_{\mathrm{l}} H_{1}^{3}}{6\left(1-\nu_{1}\right)}=\frac{\mu_{\mathrm{l}}\left(3 \kappa_{\mathrm{l}}+\mu_{\mathrm{l}}\right) H_{1}^{3}}{3\left(3 \kappa_{\mathrm{l}}+4 \mu_{\mathrm{l}}\right)}
$$

[e. g., Marguerre and Woernle (1969); $\nu_{1}=\left(3 \kappa_{1}-2 \mu_{1}\right) /\left(6 \kappa_{1}+2 \mu_{1}\right)$ is Poisson's ratio]. Even though we do not apply the thin-plate approximation here and account for two different elastic plates (crust, mantle lithosphere), this quantity controls approximately the vertical displacement of the lithosphere. Evidently, $K_{1}$ depends most strongly on $H_{l}$, which we have varied by almost one order of magnitude in the plausible range of values, so that the effect of reasonable variations of other parameters is covered as well.

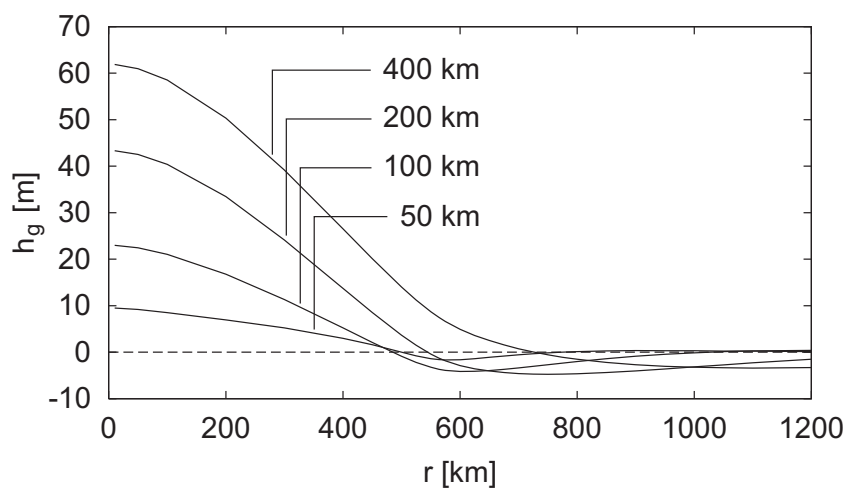

Figure 11: Computed present vertical geoid displacement, $h_{\mathrm{g}}$, as a function of radial distance from the north pole, $r$, for lithosphere thicknesses of $H_{1}=50 \mathrm{~km}, 100 \mathrm{~km}$, $200 \mathrm{~km}, 400 \mathrm{~km}$.

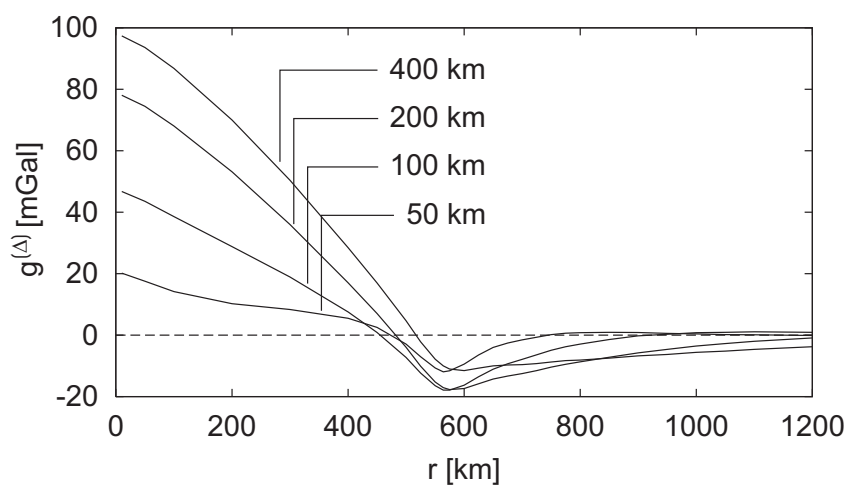

Figure 12: Computed present free-air gravity anomaly, $g^{(\Delta)}$, as a function of radial distance from the north pole, $r$, for lithosphere thicknesses of $H_{1}=50 \mathrm{~km}, 100 \mathrm{~km}, 200 \mathrm{~km}, 400 \mathrm{~km}$.

The gravity signal due to the combined effect of the mass of the NPC and its isostatic compensation is displayed in Figs. 11 and 12, which show the present vertical geoid dis- 
placement, $h_{\mathrm{g}}$ (positive upward), and the present free-air gravity anomaly, $g^{(\Delta)}$ (downward component of the vector quantity $\boldsymbol{g}^{(\Delta)}$ introduced in Sect. 2.2), respectively. As expected, both signals increase with increasing lithosphere thickness due to the smaller isostatic compensation (Fig 5). The quantities $h_{\mathrm{g}}$ and $g^{(\Delta)}$ take maximum values of some $10 \mathrm{~m}$ and some $10 \mathrm{mGal}$ near the center of the NPC and become slightly negative near the margin. As the gravity field derived from tracking the orbit of the MGS spacecraft has an accuracy of approximately $10 \mathrm{mGal}$ at the poles (Zuber et al. 2000), the signal of the NPC can in principle be resolved. However, Johnson et al. (2000), whose computed gravity anomalies agree well with our findings (see their Fig. 6), showed that the measured free-air gravity anomaly varies by more than $250 \mathrm{mGal}$ within $80^{\circ} \mathrm{N}$ and the correlation to the topography of the NPC is actually very poor, so that the signal is probably hidden by disturbances of a different origin, such as mass anomalies in the ground. Interestingly, the correlation appears to be distinctly better for the south polar cap (Smith et al. 1999b).

\section{Conclusion}

The main results of the present study are as follows:

- Present accumulation/ablation rates of $\mathcal{O}\left(0.1 \mathrm{~mm}\right.$ w.e. $\left.\mathrm{yr}^{-1}\right)$ at the surface of the NPC, which can be roughly estimated from atmospheric considerations, are consistent with the modelled ice flow.

- Present basal temperatures are far below pressure melting. Therefore, liquid water can be expected only for high salinities.

- Ice-flow velocities and accumulation/ablation rates for past obliquity maxima are one to two orders of magnitude larger than present ones (stop-and-go-type dynamics).

- Values for the present geothermal heat flux at the top of the crust that are consistent with our target ranges for present accumulation/ablation rates vary between 15 and $36 \mathrm{~mW} \mathrm{~m}^{-2}$. For the thickness of the rheological lithosphere below the NPC, the full investigated range from 50 to $400 \mathrm{~km}$ is possible.

- By employing additionally the relation between the surface heat flux and the lithosphere thickness for the more realistic depleted crust (Fig. 3), these quantities may be further constrained to $20-30 \mathrm{~mW} \mathrm{~m}^{-2}$ and 80-120 km, respectively. However, this must be taken with care due to parameter uncertainties. 
- Provided that the viscosity of the upper mantle is not more than an order of magnitude larger than the terrestrial value $\left(\sim 10^{21} \mathrm{Pas}\right)$, the mantle behaves as an inviscid fluid for the considered temporal variation and spatial extent of the ice load.

- The combined present free-air gravity signal of the NPC and the isostatic depression of the underlying ground is some $10 \mathrm{mGal}$. However, the measured signal shows variations of much larger amplitudes, so that the signal of the NPC and their compensation is hidden by mass anomalies of a different origin.

A shortcoming of the present work is that the prescribed climate history (surface temperature, ice extent) is based on very little information. For future work, it is therefore promising to include the atmospheric conditions in the modelling approach and to use the orbital elements (obliquity, eccentricity) directly as forcing functions. This can be achieved either by rather simple energy-balance considerations at the surface of the NPC (Larsen and Dahl-Jensen 2000), or by coupling a general-circulation model (GCM) for the Martian atmosphere (cf. Lewis et al. 1999 and references therein). Within a recently launched project funded by the German Science Foundation DFG (Keller et al. 2001), these ideas will be pursued.

\section{Acknowledgements}

This paper is the outcome of a presentation held on the "Second International Conference on Mars Polar Science and Exploration" (Reykjavík, Iceland, August 21-25, 2000). We wish to thank the organizers, in particular S. M. Clifford and T. Thorsteinsson, for their great commitment, which led to a lively and fruitful conference. Further, this paper benefited from the comments of K. Hutter and the reviews of T. Thorsteinsson and an anonymous referee.

\section{References}

Banerdt, W. B., M. P. Golombek and K. L. Tanaka 1992. Stress and tectonics on Mars. In Mars (H. H. Kieffer, B. M. Jakosky, C. W. Snyder and M. S. Matthews, Eds.), pp. 249-297. Univ. of Arizona Press, Tucson.

Bass, D. S. and D. A. Paige 1999. Evidence for the possible accumulation of ice at the north pole of Mars. Abstract, Fifth International Conference on Mars, Pasadena.

Breuer D., T. Spohn and U. Wüllner 1993. Mantle differentiation and the crustal dichotomy of Mars. Planet. Space Sci. 41, 269-283. 
Byrne, S. and B. C. Murray 2002. North polar stratigraphy and the paleo-erg of Mars. J. Geophys. Res. 107, 5044, doi: 10.1029/2001JE001615.

Clifford, S. M. 1987. Polar basal melting on Mars. J. Geophys. Res. 92, 9135-9152.

Clifford, S. M., D. Crisp, D. A. Fisher, K. E. Herkenhoff, S. E. Smrekar, P. C. Thomas, D. D. WynnWilliams, R. W. Zurek, J. R. Barnes, B. G. Bills, E. W. Blake, W. M. Calvin, J. M. Cameron, M. H. Carr, P. R. Christensen, B. C. Clark, G. D. Clow, J. A. Cutts, D. Dahl-Jensen, W. B. Durham, F. P. Fanale, J. D. Farmer, F. Forget, K. Gotto-Azuma, R. Grard, R. M. Haberle, W. Harrison, R. Harvey, A. D. Howard, A. P. Ingersoll, P. B. James, J. S. Kargel, H. H. Kieffer, J. Larson, K. Lepper, M. C. Malin, D. J. McCleese, B. Murray, J. F. Nye, D. A. Paige, S. R. Platt, J. J. Plaut, N. Reeh, J. W. Rice, D. E. Smith, C. R. Stoker, K. L. Tanaka, E. Mosley-Thompson, T. Thorsteinsson, S. E. Wood, A. Zent, M. T. Zuber and H. J. Zwally 2000. The state and future of Mars polar science and exploration. Icarus 144, 210-242.

Durham, W. B. 1998. Factors affecting the rheologic properties of Martian polar ice. First International Conference on Mars Polar Science and Exploration, LPI Contribution No. 953, pp. 8-9. Lunar and Planetary Institute, Houston.

Greve, R. 2000a. Waxing and waning of the perennial north polar $\mathrm{H}_{2} \mathrm{O}$ ice cap of Mars over obliquity cycles. Icarus 144, 419-431.

Greve, R. 2000b. Large-scale glaciation on Earth and on Mars. Habilitation thesis, Department of Mechanics, Darmstadt University of Technology, 274pp.

Greve, R., M. Weis and K. Hutter 1998. Palaeoclimatic evolution and present conditions of the Greenland Ice Sheet in the vicinity of Summit: An approach by large-scale modelling. Paleoclimates 2, 133-161.

Herkenhoff, K. E. and J. J. Plaut 2000. Surface ages and resurfacing rates of the polar layered deposits on Mars. Icarus 144, 243-253.

Jakosky, B. M. and R. M. Haberle 1992. The seasonal behavior of water on Mars. In Mars (H. H. Kieffer, B. M. Jakosky, C. W. Snyder and M. S. Matthews, Eds.), pp. 969-1016. Univ. of Arizona Press, Tucson.

Jakosky, B. M., B. G. Henderson and M. T. Mellon. 1993. The Mars water cycle at other epochs: Recent history of the polar caps and layered terrain. Icarus 102, 286-297.

Johnson, C. L., S. C. Solomon, J. W. Head, R. J. Phillips, D. E. Smith and M. T. Zuber 2000. Lithospheric loading by the northern polar cap on Mars. Icarus 144, 313-328.

Keller, H. U., D. Titov, B. Grieger, K. Fraedrich and R. Greve 2001. Investigation of the current and ancient Martian climate, its stability and mechanisms of changes by means of a modular planet simulator model. Proposal to the German Science Foundation DFG.

Kieffer, H. H. and A. P. Zent 1992. Quasi-periodic climate change on Mars. In Mars (H. H. Kieffer, B. M. Jakosky, C. W. Snyder and M. S. Matthews, Eds.), pp. 1180-1218. Univ. of Arizona Press, Tucson.

Klemann, V. and D. Wolf 1999. Implications of a ductile crustal layer for the deformation caused by the Fennoscandian ice sheet. Geophys. J. Int. 139, 216-226.

Klemann, V., P. Wu and D. Wolf 2003. Compressible viscoelasticity: Stability of solutions for homogeneous plane earth models. Geophys. J. Int. (in press). 
Larsen, J. and D. Dahl-Jensen 2000. Interior temperatures of the northern polar cap on Mars. Icarus 144, 456-462.

Laskar, J., B. Levrard and J. F. Mustard 2002. Orbital forcing of the martian polar layered deposits. Nature 419, 375-377.

Lewis, S. R., M. Collins, P. L. Read, F. Forget, F. Hourdin, R. Fournier, C. Hourdin, O. Talagrand and J.-P. Huot 1999. A climate database for Mars. J. Geophys. Res. 104, 24177-24194.

Marguerre, K. and H.-T. Woernle 1969. Elastic plates. Blaisdell Publishing Company, Waltham, Mass., etc., 214 pp.

McKenzie, D. and M. J. Bickle 1988. The volume and composition of melt generated by extension of the lithosphere. J. Petrol. 26, 625-679.

Meissner, R. O. and U. R. Vetter 1979. Relationship between the seismic quality factor $Q$ and the effective viscosity $\eta^{\star}$. J. Geophys. 45, 147-158.

Nye, J. F. 2000. A flow model for the polar caps of Mars. J. Glaciol. 46, 438-444.

Parmentier, E. M. and O. Grasset 1998. Thermal convection in a volumetrically heated, infinite Prandtl number fluid with strongly temperature-dependent viscosity: Implications for planetary thermal evolution. J. Geophys. Res. 103, 18171-18181.

Paterson, W. S. B. 1994. The physics of glaciers. Third edition. Oxford, etc., Pergamon Press, 480 pp.

Schubert, G., S. C. Solomon, D. L. Turcotte, M. J. Drake and N. H. Sleep 1992. Origin and thermal evolution of Mars. In Mars (H. H. Kieffer, B. M. Jakosky, C. W. Snyder and M. S. Matthews, Eds.), pp. 147-183. Univ. of Arizona Press, Tucson.

Smith, D. E., M. T. Zuber, S. C. Solomon, R. J. Phillips, J. W. Head, J. B. Garvin, W. B. Banerdt, D. O. Muhleman, G. H. Pettengill, G. A. Neumann, F. G. Lemoine, J. B. Abshire, O. Aharonson, C. D. Brown, S. A. Hauck, A. B. Ivanov, P. J. McGovern, H. J. Zwally and T. C. Duxbury 1999a. The global topography of Mars and implications for surface evolution. Science 284, 1495-1503.

Smith, D. E., W. L. Sjogren, G. L. Tyler, G. Balmino, F. G. Lemoine and A. S. Konopliv 1999b. The gravity field of Mars: Results from Mars Global Surveyor. Science 286, 94-97.

Sohl, F. and T. Spohn 1997. The interior structure of Mars: Implications from SNC meteorites. J. Geophys. Res. 102, 1613-1635.

Solomon, S. C. and J. W. Head 1990. Heterogeneities in the thickness of the elastic lithosphere of Mars: Constraints on heat flow and internal dynamics. J. Geophys. Res. 95, 11073-11083.

Spohn, T., F. Sohl and D. Breuer 1998. Mars. Astron. Astrophys. Rev. 8, 181-235.

Svendsen, B. and K. Hutter 1996. A continuum approach for modelling induced anisotropy in glaciers and ice sheets. Ann. Glaciol. 23, 262-269.

Thomas, P., S. Squyres, K. Herkenhoff, A. Howard and B. Murray 1992. Polar deposits of Mars. In Mars (H. H. Kieffer, B. M. Jakosky, C. W. Snyder and M. S. Matthews, Eds.), pp. 767-795. Univ. of Arizona Press, Tucson.

Touma, J. and J. Wisdom 1993. The chaotic obliquity of Mars. Science 259, 1294-1297. 
Ward, W. R. 1992. Long-term orbital and spin dynamics of Mars. In Mars (H. H. Kieffer, B. M. Jakosky, C. W. Snyder and M. S. Matthews, Eds.), pp. 298-320. Univ. of Arizona Press, Tucson.

Wolf, D. 1985a. The normal modes of a layered, incompressible Maxwell half-space. J. Geophys. 57, $106-117$.

Wolf, D. 1985b. The normal modes of a uniform, compressible Maxwell half-space. J. Geophys. 56, $100-105$.

Wu, P. and W. R. Peltier 1982. Viscous gravitational relaxation. Geophys. J. R. Astr. Soc. 70, 435-485.

Wüllner, U. and H. Harder 1998. Convection underneath a crust inhomogeneously enriched in heat sources: application to martian mantle dynamics. Phys. Earth Planet. Int. 109, 129-150.

Zuber, M. T., D. E. Smith, S. C. Solomon, J. B. Abshire, R. S. Afzal, O. Aharonson, K. Fishbaugh, P. G. Ford, H. V. Frey, J. B. Garvin, J. W. Head, A. B. Ivanov, C. L. Johnson, D. O. Muhleman, G. A. Neumann, G. H. Pettengill, R. J. Phillips, X. Sun, H. J. Zwally, W. B. Banerdt and T. C. Duxbury 1998. Observations of the north polar region of Mars from the Mars Orbiter Laser Altimeter. Science 282, 2053-2060.

Zuber, M. T., S. C. Solomon, R. J. Phillips, D. E. Smith, G. L. Tyler, O. Aharonson, G. Balmino, W. B. Banerdt, J. W. Head, C. L. Johnson, F. G. Lemoine, P. J. McGovern, G. A. Neumann, D. D. Rowlands and S. Zhong 2000. Internal structure and early thermal evolution of Mars from Mars Global Surveyor topography and gravity. Science 287, 1788-1793. 